\title{
Effect of potassium-sparing diuretics on the renin- angiotensin-aldosterone system and potassium retention in heart failure
}

\author{
M. G. Nicholls', E. A. Espiner, H. Hughes, and T. Rogers \\ From the Medical Unit, The Princess Margaret Hospital, Christchurch 2, New Zealand
}

The renin-angiotensin-aldosterone system and electrolyte levels in 11 patients with heart failure controlled on digoxin and frusemide were investigated after separate periods of Slow $K$, spironolactone, and amiloride therapy. When spironolactone or amiloride replaced Slow $K$, distinct parallel increments in the levels of renin, angiotensin II, and aldosterone resulted. Though plasma potassium was generally higher after spironolactone and amiloride than after Slow $K$, exchangeable potassium was similar with the three regimens. There was no significant relation between plasma potassium and concurrent exchangeable potassium.

Total body potassium tends to be low in patients with cardiac failure (Singh, Hurley, and North, 1969; White et al., 1969), and hypokalaemia is a frequent complication of conventional diuretic therapy in these patients (Sandoe and Olesen, 1962). Supplements of potassium are, therefore, advocated but doubt remains as to their efficacy (Down et al., 1972). More recently, other potassium-sparing agents, such as spironolactone and amiloride have been promoted as means of conserving potassium, but these drugs have not yet been proved clearly superior in increasing body potassium. One reason for this could be the development of hyperaldosteronism, since in addition to any effect on plasma potassium concentration both amiloride and spironolactone are natriuretic and may further increase aldosterone secretion by augmenting renin and angiotensin production.

These relations have been explored in the present study in which the comparative effects of spironolactone, amiloride, and potassium supplements on the renin-angiotensin-aldosterone system have been studied together with changes in plasma, urine, and exchangeable potassium in 11 patients receiving maintenance diuretic therapy for congestive cardiac failure.

Received 20 April 1976.

'Present address: M.R.C. Blood Pressure Unit, Western Infirmary, Glasgow G11 6NT, Scotland.

\section{Methods}

Eleven patients, ages 33 to 73 years, were studied (Table) after obtaining informed consent. All had previously been treated for congestive heart failure with conventional glycoside and diuretic treatment and were free from oedema at the time of admission to the study. After discharge from hospital, all but 2 patients received potassium supplements in the form of Slow $\mathrm{K}$ for at least 4 weeks (range 4 weeks to 3 years). The patients continued to take digoxin $(0.0625$ to $0.75 \mathrm{mg}$ daily in different patients) and frusemide (40 to $160 \mathrm{mg} / \mathrm{d}$ ) at a constant dose, chosen by clinical criteria, for the duration of the study. Spironolactone or amiloride were substituted for Slow $\mathrm{K}$ at intervals of 2 months in each patient. In 4 patients amiloride was given first followed by spironolactone while in 5 , spironolactone treatment preceded amiloride (see Table). Two patients (Cases 1 and 3) received treatment with only one potassium-sparing diuretic (spironolactone). Doses of potassium supplements ( 24 to 48 $\mathrm{mmol} /$ day), amiloride (10 to $15 \mathrm{mg} /$ day), and spironolactone (100 mg/day) were chosen on clinical grounds and were held constant in any one patient for each treatment period. These details together with other essential drug therapy taken by the patients throughout the study are listed in the Table.

After each treatment period, the patient was admitted to hospital for 26 hours and measurements 
TABLE Clinical, electrolyte, and treatment data

\begin{tabular}{|c|c|c|c|c|c|c|c|c|}
\hline $\begin{array}{l}\text { Case } \\
\text { No. }\end{array}$ & Sex & $\begin{array}{l}\text { Age } \\
(y)\end{array}$ & $\begin{array}{l}\text { Body } \\
\text { weight } \\
\text { (kg) }\end{array}$ & Aetiology of heart failure & Other disorders & $\begin{array}{l}\text { Frusemide } \\
\text { dose } \\
\text { (mg/day) }\end{array}$ & $\begin{array}{l}\text { Assessmer } \\
\text { electrolyt } \\
\text { (mmol/d) } \\
\text { Sodium }\end{array}$ & $\begin{array}{l}\text { of dietary } \\
\text { intake } \\
\text { Potassium }\end{array}$ \\
\hline 1 & $\mathbf{M}$ & 57 & $66 \cdot 4$ & $\begin{array}{l}\text { Ischaemic heart disease; } \\
\text { chronic airways disease } \neq\end{array}$ & 一 & 160 & 63 & 62 \\
\hline 2 & $\mathbf{M}$ & 73 & $57 \cdot 2$ & Ischaemic heart disease & 一 & 80 & 180 & 77 \\
\hline 3 & $\mathbf{M}$ & 72 & $68 \cdot 5$ & Ischaemic heart disease & 一 & 120 & 126 & 45 \\
\hline 4 & $\mathbf{M}$ & 55 & $101 \cdot 4$ & Idiopathic cardiomyopathy & Gout & 80 & 129 & 59 \\
\hline 5 & $\mathbf{F}$ & 33 & $82 \cdot 6$ & Idiopathic cardiomyopathy & Obesity & 80 & 120 & 55 \\
\hline 6 & $\mathbf{M}$ & 73 & $70 \cdot 8$ & Ischaemic heart disease & Diabetes mellitus & 40 & 116 & 60 \\
\hline 7 & $\mathbf{M}$ & 60 & $83 \cdot 2$ & Ischaemic heart disease & 一 & 40 & 50 & 38 \\
\hline 8 & $\mathbf{M}$ & 46 & $99 \cdot 6$ & Alcoholic cardiomyopathy & $\begin{array}{l}\text { Chronic airways disease; } \\
\text { obesity }\end{array}$ & 160 & 120 & 90 \\
\hline 9 & $\mathbf{M}$ & 68 & $73 \cdot 8$ & $\begin{array}{l}\text { Ischaemic heart disease; } \\
\text { chronic airways disease }\end{array}$ & 一 & 80 & 110 & 66 \\
\hline 10 & $\mathbf{M}$ & 54 & $97 \cdot 2$ & Ischaemic heart disease & $\begin{array}{l}\text { Hypertension; gout; obesity; } \\
\text { diabetes mellitus }\end{array}$ & 80 & 165 & 96 \\
\hline 11 & $\mathbf{F}$ & 64 & $87 \cdot 8$ & Ischaemic heart disease & $\begin{array}{l}\text { Obesity; diabetes mellitus, } \\
\text { hyperthyroidism }\end{array}$ & 80 & 50 & 40 \\
\hline
\end{tabular}

*In addition to digoxin, frusemide, and a potassium-sparing agent.

$\dagger$ Mean of two estimations in most cases: determined while receiving Slow $\mathbf{K}$ therapy.

¥Severe airways disease with $\mathrm{CO}_{2}$ retention.

of exchangeable potassium and plasma volume were made. In addition, blood was drawn at 8 a.m. (overnight supine), 9 a.m. (after one hour of upright posture), 12 noon, 4 p.m., and 8 p.m. (free posture) for measurement of plasma renin activity (PRA) (Haber et al., 1969), angiotensin II (AII) (Nicholls and Espiner, 1975), aldosterone (Ito et al., 1972), and sodium and potassium. Simultaneous samples for cortisol determination (Murphy, 1967) were drawn in 8 of the 11 patients. Twenty-four-hour urinary electrolytes, creatinine and aldosterone (Bayard et al., 1970) excretion were measured in urines collected on the day before, as well as on the day of hospital admission. In addition, full clinical assessment of cardiac status, chest $x$-ray, electrocardiogram, and measurements of creatinine clearance were carried out at the completion of each treatment period.

For the determination of exchangeable potassium $\left(\mathrm{K}_{\mathrm{E}}\right)$ a precisely measured quantity (approximately $100 \mu \mathrm{Ci}$ ) of ${ }^{42} \mathrm{~K}$ was given orally and the $\mathrm{K}_{\mathrm{E}}$ was calculated (Belcher and Vetter, 1971) from specific activity determined in a urine sample obtained 24 to 25 hours after the isotope's administration. Plasma volume was determined using ${ }^{125} \mathrm{I}$-labelled albumin. Normal values in this laboratory for subjects on unrestricted diets are as follows: 9 a.m. ambulant PRA 0.46 to $2.31 \mathrm{nmol} / 1$ per $\mathrm{hr}(600$ to $3000 \mathrm{pg} / \mathrm{ml} \mathrm{per} \mathrm{hr}$ ), AII 19 to $79 \mathrm{pmol} / 1$ (20 to 83 $\mathrm{pg} / \mathrm{ml}$ ), and plasma aldosterone 0.14 to $0.56 \mathrm{nmol} / 1$ ( 5 to $20 \mathrm{ng} / 100 \mathrm{ml}$ ); plasma cortisol $0 \cdot 14$ to $0 \cdot 84$ $\mu \mathrm{mol} / 1$ (5 to $30 \mu \mathrm{g} / 100 \mathrm{ml}$ ); urine aldosterone excretion 13.9 to $50 \mathrm{nmol} / \mathrm{d}$ ( 5 to $18 \mu \mathrm{g} / \mathrm{d}$ ). During the study, the patients were on an unrestricted diet which was not altered during the hospital admission. Each patient's electrolyte intake was assessed at least once during the study by a dietitian.

Statistical analyses (correlation coefficients and paired t-tests) were made using a Hewlett-Packard $9810 \mathrm{~A}$ calculator.

\section{Results}

\section{General}

General health and cardiac status of all patients remained unchanged throughout the study period except in Case 9 who developed an exacerbation of cardiac failure while receiving spironolactone and in Case 1 who died suddenly shortly after starting amiloride. One patient (Case 3) withdrew from the study because he considered his health optimal on spironolactone.

Body weight was lower after spironolactone (mean fall $1.4 \mathrm{~kg}$ ) and amiloride (mean fall $1.3 \mathrm{~kg}$ ) compared to body weight measured after potassium supplements, but the differences were not significant $(\mathrm{P}>0.5)$. Plasma creatinine and creatinine clearance were not significantly altered by any of the treatment regimens. Plasma urea, however, was higher after spironolactone (mean $47 \pm 4 \cdot 1$ SEM $\mathrm{mg} / 100 \mathrm{ml}$ ) than Slow $K$ therapy (mean $31 \pm 5.1 \quad P<0.05$ ) or amiloride (mean $38 \cdot 7 \pm 2 \cdot 8 \quad \mathrm{P}>0 \cdot 2$ ). Venous $p \mathrm{H}$, 


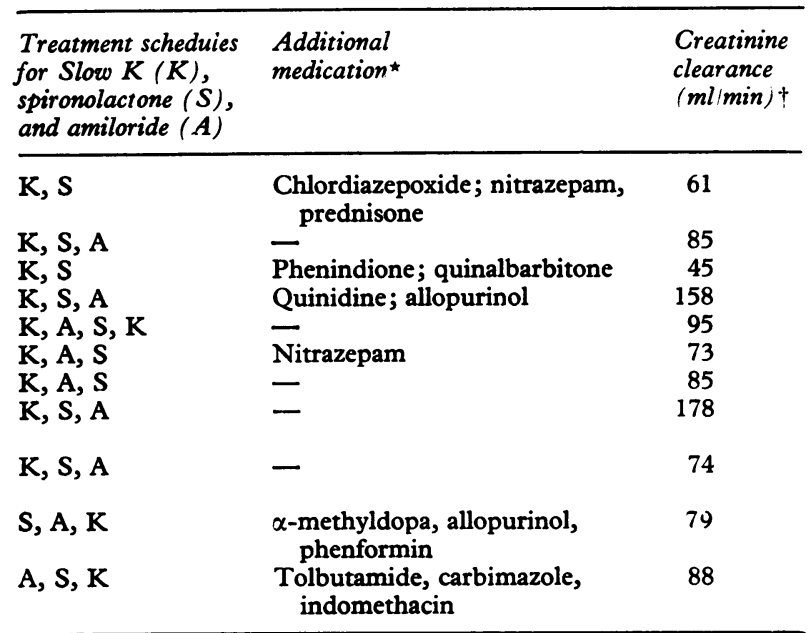

bicarbonate, and total $\mathrm{CO}_{2}$ concentration were not significantly altered in any treatment regimen.

\section{Renin-angiotensin-aldosterone system}

PRA, AII, and plasma aldosterone levels were mostly within normal lim.its after Slow $\mathrm{K}$ therapy, but were clearly increased by amiloride and spironolactone (Fig. 1). Proportionate changes in PRA, AII, and plasma aldosterone were seen within each treatment group. For all three hormones, the 9 a.m. upright value was significantly higher after the potassium-sparing diuretics than that seen after Slow $K$ therapy $(P<0.01)$. The 9 a.m. upright PRA and AII values after treatment with spironolactone were significantly higher $(P<0.05$ and $P<0.01$, respectively) than those measured after amiloride, but the difference in plasma aldosterone failed to attain significance. That the lower hormone values after Slow $\mathrm{K}$ therapy were not dependent on the order of drug regimen used is shown by the similarity of findings in Cases 10 and 11 in whom Slow $\mathrm{K}$ therapy was the final treatment administered. Further, as shown in Fig. 2, reinstitution of Slow $\mathrm{K}$ therapy after potassium-sparing diuretics in Case 5 was accompanied by decrements in hormone concentrations to values observed initially. When hormone interrelations were analysed from the 5 plasma samples drawn on each hospital admission, PRA and AII levels were closely correlated in individual patients (range of $r$ values 0.72 to 0.96 ,

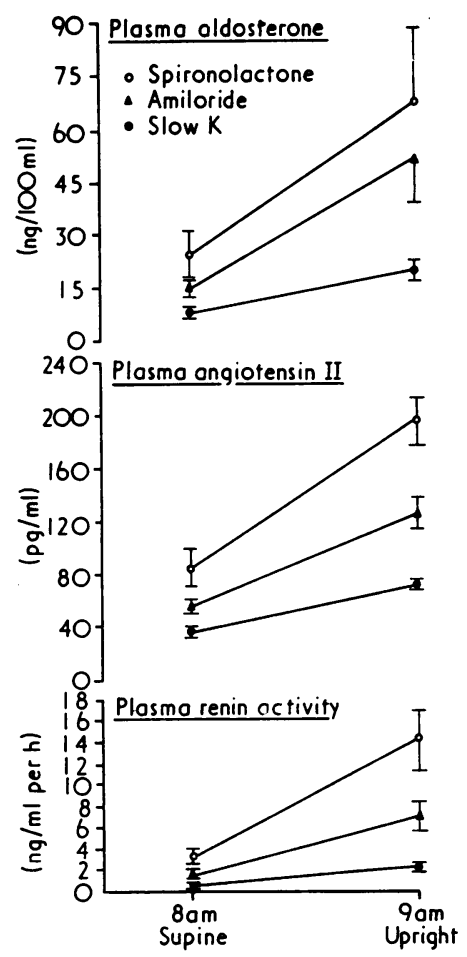

FIG. 1 Plasma aldosterone, angiotensin II, and $P R A$ values (mean \pm standard error of the mean) in 11 patients receiving potassium-sparing drug regimens. 8 a.m. (overnight supine) and 9 a.m. (1 hour of upright posture) levels are shown. Conversion factors are: for plasma aldosterone $1 \mathrm{nmol} / \mathrm{l}=36 \mathrm{ng} / 100 \mathrm{ml}$; $P R A 1 \mathrm{nmol} / \mathrm{l}$ per $\mathrm{hr}=1.3 \mathrm{ng} / \mathrm{ml} \mathrm{per} \mathrm{hr}$; angiotensin II $1 \mathrm{pmol} / \mathrm{l}=1.05 \mathrm{pg} / \mathrm{ml}$.

$P<0.01$ to $P<0.001, n=10$ to 15$)$ and for the group as a whole $(r=0.75 \quad P<0.001, n=154)$. Likewise, fluctuations in AII and plasma aldosterone were statistically related overall $(r=0.72, P<0.001$, $\mathrm{n}=154)$ and in individuals $(\mathrm{r}=0.60$ to 0.95 , $P<0.02$ to $P<0.001, n=10$ to 15$)$ except in one patient (Case 2) where statistical significance was not achieved $(P>0.05)$. Plasma cortisol levels were, with few exceptions, within the normal range, and a diurnal pattern (highest level at 8 a.m. lowest at 8 p.m.) was usually seen. There was no correlation between concurrent plasma cortisol and aldosterone levels in 6 subjects $(P>0.05)$, though in 2 others the $r$ values $(0.54,0.79)$ were significant $(P<0.05)$.

Urine aldosterone excretion reflected the changes observed in plasma hormone concentrations. After Slow $\mathrm{K}$ therapy, urine aldosterone was within normal limits (mean 25, range 11 to $50 \mathrm{nmol} /$ day) 


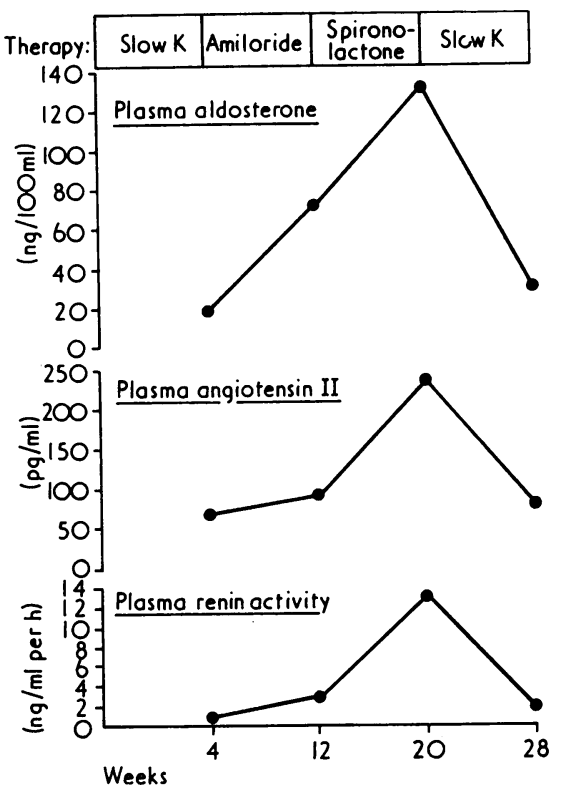

FIG. 2 Plasma aldosterone, angiotensin II, and $P R A$ in Case 5 after three different potassium-sparing drug regimens. Potassium supplements were administered on two different occasions, at the beginning and end of the study. Values shown are the mean of 5 estimations. See legend for Fig. 1 for conversion to SI units.

but was increased by amiloride (mean 64, range 31 to $125 \mathrm{nmol} /$ day) and by spironolactone (mean 75 , range 33 to $167 \mathrm{nmol} /$ day).

\section{Electrolyte levels}

Changes in plasma potassium and sodium concentration, urine sodium/potassium ratio, and exchangeable potassium are shown for each of the 3 treatment periods in Fig. 3. Compared with levels after Slow $\mathrm{K}$ therapy, plasma potassium was higher after spironolactone $(P<0.05)$ but the increments seen after amiloride failed to achieve significance $(\mathbf{P}>0 \cdot 2)$. Plasma sodium fell after spironolactone $(P<0.025)$ and both spironolactone and amiloride caused an appreciable increase in the urine $\mathrm{Na} / \mathrm{K}$ ratio $(P<0.05)$, in comparison with Slow $K$ therapy. Despite these changes in the urine $\mathrm{Na} / \mathrm{K}$ ratio and in plasma potassium, no significant change in $K_{E}$ was seen after treatment with either amiloride or spironolactone. Values for $\mathrm{K}_{\mathrm{E}}$ were usually within the reported normal range (Flear et al., 1966), though 2 patients (Cases 3 and 7) had low values. $\mathrm{K}_{\mathrm{E}}$ after Slow K (mean 2905, range 2170 to 4413 mmol) was altered variably and insignificantly by spironolactone (mean 2715, range 1759 to 4109 $\mathrm{mmol}$ ) and amiloride (mean 2864, range 1985 to $3815 \mathrm{mmol}$ ). Comparison of $\mathrm{K}_{\mathrm{E}}$ values according to body weight or height (Fig. 3) or on the basis of body surface area likewise indicated no significant difference between the three treatment regimens $(P>0 \cdot 2)$. For the group as a whole, there was no significant correlation between mean plasma potassium and concurrent $K_{E}$ values $(r=0 \cdot 03)$. However, dietary potassium intake (as assessed by a dietitian) was significantly related to the mean $K_{E}$ value for each patient $(r=0.60, P<0.02) . K_{E}$ did not correlate with either frusemide dosage or with the level of urine or plasma aldosterone $(P>0 \cdot 2)$.

Plasma volume measured after Slow $K$ therapy (mean $3 \cdot 2 \pm 0 \cdot 2$ SEM litres) was not significantly altered by substitution with either spironolactone (mean $3 \cdot 1 \pm 0 \cdot 2$ SEM litres) or amiloride (mean

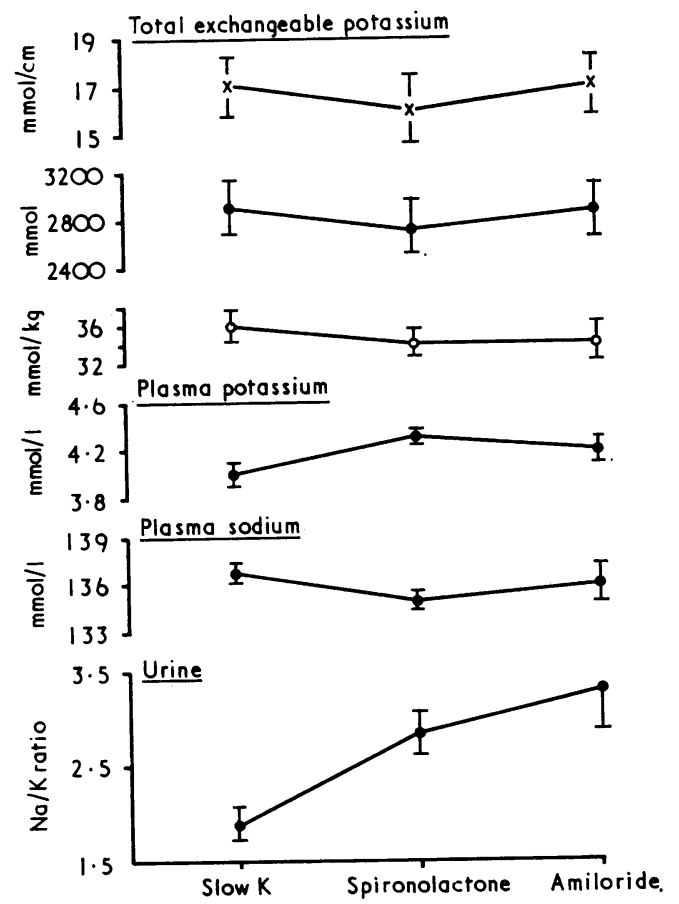

FIG. 3 Total body exchangeable potassium and electrolyte values measured concurrently after potassium supplements, spironolactone, and amiloride in 11 patients with cardiac failure. For exchangeable potassium, levels are shown according to body weight ( $\mathrm{mmol} / \mathrm{kg}$ ) and body height $(\mathrm{mmol} / \mathrm{cm})$ in addition to total body potassium. Mean \pm SEM values are shown. 
$3 \cdot 3 \pm 0.2$ SEM litres $)(P>0 \cdot 4)$. No relation between plasma volume and either PRA-AII concentrations (determined on the same day), or the dosage of frusemide, was found in this study.

\section{Discussion}

These results show that significant hyperaldosteronism occurs in patients with heart failure when potassium-sparing diuretic drugs are added to conventional drug therapy. Hormone levels were unremarkable before the addition of amiloride or spironolactone despite doses of frusemide up to $160 \mathrm{mg}$ daily. Since previous studies (Espiner et al., 1969; Nicholls et al., 1974) have shown that hyperaldosteronism frequently occurs towards the end of the diuretic phase in oedematous patients receiving frusemide, it appears that 'adaptation' of the reninangiotensin system may occur with maintenance frusemide therapy, similar to that described in hypertensive patients receiving chronic diuretic therapy (Bourgoignie, Catanzaro, and Perry, 1968). Throughout the study, a close relation was observed between PRA and AII, and both of these indices were significantly correlated with plasma and urine aldosterone. While the increment in plasma potassium may also have contributed to aldosterone hypersecretion during spironolactone therapy, this was not likely after amiloride which at the doses used did not significantly raise plasma potassium.

From the cortisol data, ACTH did not dictate the observed aldosterone fluctuations. These findings, therefore, are consistent with a dominant role for AII in the control of aldosterone in patients treated with diuretics. Hitherto increases in plasma AII have been regarded important only in so far as they affect aldosterone and electrolyte metabolism. The recent demonstration that AII may contribute to myocardial necrosis in experimental animals (Gavras et al., 1975) brings an additional note of caution, particularly in view of the very high levels of AII produced in some of our patients who had impaired myocardial function.

Whether the raised levels of renin, AII, and aldosterone would be sustained after more prolonged treatment with amiloride or spironolactone, cannot be confidently predicted from the current work. Nevertheless, the fact that the hormone levels were clearly increased after concurrent two-month periods of treatment with these 2 agents supports a long-term stimulatory effect of amiloride and spironolactone on the renin-angiotensin-aldosterone system.

Although clear-cut increases in the urine sodium/ potassium ratio after both amiloride and spironolactone and in plasma potassium after spirono- lactone were seen in our patients, there was no significant alteration in $\mathrm{K}_{\mathrm{E}}$. The expression of $\mathrm{K}_{\mathrm{E}}$ in terms of body weight or height did not alter this conclusion. Previous studies in heart failure patients, though showing an improvement in plasma potassium in most cases (Friis, 1972; Croxson, Neutze, and John, 1972; Davidson and Gillebrand, 1973; Carney, Wilson, and Morgan, 1974), have variously reported increases (Friis, 1972; Carney et al., 1974), or no change (Croxson et al., 1972; Davidson and Gillebrand, 1973) in $\mathrm{K}_{\mathrm{E}}$ during therapy with potassium-sparing diuretics. It is possible that more prolonged therapy might shown increases in $\mathrm{K}_{\mathrm{E}}$, but this is not supported by our study when comparison was made between $K_{E}$ before and after two successive two-month potassium-sparing drug treatments. The development of hyperaldosteronism may possibly limit potassium conservation in amiloride-treated patients, but this seems unlikely with spironolactone where the drug competes with aldosterone at the receptor site-as indicated by the sustained increase in both plasma potassium and in the urine sodium/potassium ratios observed in our patients. In common with other studies (Croxson et al., 1972; Flear, Cooke, and Quinton, 1957; De Deuxchaisnes et al., 1961), there was no correlation of plasma potassium with $\mathrm{K}_{\mathrm{E}}$. However, a significant correlation of mean $\mathrm{K}_{\mathrm{E}}$ was found with the estimated dietary potassium intake. Details of the influence of plasma potassium concentration and of total body potassium upon myocardial function and on the risk of complications from digitalis therapy in heart failure patients remain to be clarified.

In conclusion, the addition of conventional doses of spironolactone or amiloride to diuretic treatment in patients with congestive heart failure did not alter $\mathrm{K}_{\mathrm{E}}$ but induced significant hyperaldosteronism. Aldosterone hypersecretion was more significantly related to hyper-reninism than to potassium retention.

We are grateful to Merck, Sharp, and Dohme Ltd. for supplying amiloride. This work received support from the Medical Research Council of New Zealand and the New Zealand Heart Foundation.

\section{References}

Bayard, F., Beitins, I. Z., Kowarski, A., and Migeon, C. J. (1970). Measurement of aldosterone secretion rate by radioimmunoassay. Fournal of Clinical Endocrinology and Metabolism, 31, 507.

Belcher, E. H., and Vetter, H. (1971). (Eds.) Radioisotopes in Medical Diagnosis, p. 271. Butterworths, London.

Bourgoignie, J. J., Catanzaro, F. J., and Perry, H. M. (1968). Renin-angiotensin-aldosterone system during chronic thiazide therapy of benign hypertension. Circulation, 37, 27. 
Carney, S., Wilson, M., and Morgan, T. (1974). Potassium depletion associated with thiazide diuretics in patients with hypertension or congestive cardiac failure. Australian and New Zealand fournal of Medicine, 4, 425.

Croxson, M. S., Neutze, J. M., and John, M. B. (1972). Exchangeable potassium in heart disease; long-term effects of potassium supplements and amiloride. American Heart fournal, 84, 53.

Davidson, C., and Gillebrand, I. M. (1973). Use of amiloride as a potassium conserving agent in severe cardiac disease. British Heart fournal, 35, 456.

De Deuxchaisnes, C. N., Collet, R. A., Busset, R., and Mach, R. S. (1961). Exchangeable potassium in wasting, amyotrophy, heart-disease, and cirrhosis of the liver. Lancet, 1,681 .

Down, P. F., Polak, A., Rao, R., and Mead, J. A. (1972). Fate of potassium supplements in six outpatients receiving long-term diuretics for oedematous disease. Lancet, 2, 721 .

Espiner, E. A., Jagger, P. I., Tucci, J. R., and Lauler, D. P. (1969). Effect of acute diuresis on aldosterone secretion in edematous patients. New England fournal of Medicine, 280, 1141 .

Flear, C. T. G., Cooke, W. T., and Quinton, A. (1957). Serum-potassium levels as an index of body content. Lancet, 1, 458.

Flear, C. T. G., Quinton, A., Carpenter, R. G., Domenet, J. G., and Sivyer, A. (1966). Exchangeable body potassium and sodium in patients in congestive heart failure. Clinica Chimica Acta, 13, 1.

Friis, T. (1972). Exchangeable sodium and potassium during spironolactone therapy. In Extrarenal Activity of Aldosterone and its Antagonists, p. 35 . Excerpta Medica, Amsterdam.

Gavras, H., Kremer, D., Brown, J. J., Gray, B., Lever, A. F., MacAdam, R. F., Medina, A., Morton, J. J., and Robertson, J. I. S. (1975). Angiotensin- and norepinephrineinduced myocardial lesions: experimental and clinical studies in rabbits and man. American Heart fournal, 89, 321.
Haber, E., Koerner, T., Page, L. B., Kliman, B., and Purnode, A. (1969). Application of a radioimmunoassay for angiotensin I to the physiologic measurements of plasma renin activity in normal human subjects. Fournal of Clinical Endocrinology and Metabolism, 29, 1349.

Ito, T., Woo, J., Haning, R., and Horton, R. (1972). A radioimmunoassay for aldosterone in human peripheral plasma including a comparison of alternate techniques. Fournal of Clinical Endocrinology and Metabolism, 34, 106.

Murphy, B. E. P. (1967). Some studies of the protein-binding of steroids and their application to the routine micro and ultramicro measurement of various steroids in body fluids by competitive protein-binding radioassay. Fournal of Clinical Endocrinology and Metabolism, 27, 973.

Nicholls, M. G., and Espiner, E. A. (1975). A radioimmunoassay method for measuring angiotensin II. New Zealand Medical fournal, 81, 490.

Nicholls, M. G., Espiner, E. A., Donald, R. A., and Hughes, $H$. (1974). Aldosterone and its regulation during diuresis in patients with gross congestive heart failure. Clinical Science and Molecular Medicine, 47, 301.

Sandoe, E., and Olesen, K. H. (1962). Hypokalaemia, hypochloraemia and baseosis in long-term treatment of oedematous heart failure with benzothiadiazine diuretics. Acta Medica Scandinavica, 172, 691

Singh, B. N., Hurley, P. J., and North, J. D. K. (1969). The use of amiloride in potassium depletion before cardiac surgery. American Heart fournal, 78, 22.

White, R. J., Chamberlain, D. A., Hamer, J., McAlister, J., and Hawkins, L. A. (1969). Potassium depletion in severe heart disease. British Medical fournal, 2, 606.

Requests for reprints to Dr. M. G. Nicholls, M.R.C. Blood Pressure Unit, Western Infirmary, Glasgow G11 6NT. 